\title{
ESPAÑA Y LA LITERATURA DE VIAJES EN EL SIGLO XIX*
}

\author{
Ana $\mathrm{M}^{\mathrm{a}}$ FREIRE \\ UNED. Madrid
}

\section{RESUMEN}

Reproduce este artículo el texto de una conferencia pronunciada en un ciclo sobre Alicante y su provincia en la literatura de viajes. En ella se traza una panorámica de esta modalidad literaria, referida a la España del siglo XIX, en la que se abordan las motivaciones que hacen surgir el género, los aspectos formales y estilísticos que la caracterizan y diferencian de la del siglo precedente o los itinerarios preferidos por los viajeros, con atención particular a las obras en que sus autores, tanto españoles como extranjeros, se ocuparon de Alicante.

Palabras clave: Literatura de viajes, Literatura española del siglo XIX, Espacio urbano y literatura

\section{ABSTRACT}

This article contains the text of a lecture given on Alicante y su provincia en la literatura de viajes. The author gives in it a panoramic view of this literary gender in the Spanish XIX ${ }^{\text {th }}$ century. She studies the gender motivations, the formal and stylistic aspects that characterize and differentiate it from the travel literature of the preceding century or the routes that travelers prefer, with special attention to the books in which their authors, both Spanish and foreigners, wrote about Alicante.

Key words: Travel Literature, Spanish Literature XIX ${ }^{\text {th }}$ century, Urban Space and Literature.

\footnotetext{
* Conferencia pronunciada en el ciclo organizado por el Instituto Alicantino de Cultura «Juan Gil-Albert» sobre Alicante y su provincia en la literatura de viajes.
} 
El XIX fue el gran siglo de la literatura de viajes, y desde luego de la literatura de viajes por España, que fue el destino preferido por muchos ilustres viajeros de otros países que visitaron el nuestro, envuelto entonces en un halo de leyenda que ellos mismos se encargaron de difundir y de aumentar.

Antes del siglo XIX se viajaba menos (viajaban menos personas) y después del XIX viajan (o viajamos) muchas más, pero, por lo general, no se escribe el viaje. Los medios de comunicación han acortado las distancias y todos conocemos de algún modo lugares que nunca hemos visitado.

La etapa dorada o Edad de Oro de la literatura de viajes que es el siglo XIX se inicia en España en la época romántica. Entre las manías del siglo, Mesonero Romanos consideraba que la más digna de atención era la de viajar:

Este deseo de agitación y perpetuo movimiento, este malestar indefinible, que sin cesar nos impele y bambolea material y moralmente, sin permitirnos un instante de reposo; siempre con la vista fija en un punto distante del que ocupamos; siempre el pie en el estribo, el catalejo en la mano, deseando llegar al sitio adonde nos dirigimos; ansiando, una vez llegados, volver al que abandonamos, y con pena de no poder examinar los que a derecha e izquierda alcanzamos a ver (Mesonero, 1881: 1).

Y es que en el siglo XIX nacen el viaje de placer, los viajes organizados, las guías... No quiere esto decir que no existan ya viajes como los del XVIII que, en palabras de Gómez de la Serna (1974), eran una verdadera aventura intelectual (el viaje científico, el histórico, el geográfico), sino que surge este nuevo modo de recorrer el mundo que es el viaje de recreo. ${ }^{1}$ Desde mediados de siglo encontramos manuales y guías útiles para los viajeros. Pero no es a este tipo de obras a las que me quiero referir al hablar de literatura de viajes, porque las guías y los manuales no pueden considerarse, casi nunca, literatura, ni lo pretenden. Los propios escritores lo saben: «Yo no escribo guías; voy a donde me lleva mi capricho, a lo que excita mi fantasía, al señuelo de lo que distingue a una población entre las demás», afirmaba Emilia Pardo Bazán (Pardo Bazán, 1895:121).

El auge de los viajes tuvo mucho que ver con la creciente mejora de las vías de comunicación, de los transportes e incluso de los alojamientos. Pero Mesonero, que no menciona estas razones, sino otras, como incentivos para recorrer mundo, añade irónicamente una que afecta directamente al tema que nos ocupa:

Hay $[\ldots]$ otro motivillo más para que en este siglo fugaz y vaporoso todo hombre honrado se determine a ser viajador. Y este motivo no es otro

1. No es mi propósito abundar en la idea del grand tour practicado por los extranjeros, sobre el que existe amplia bibliografía. 
(perdónenme la indiscreción si la descubro) que la intención que simultáneamente forma de hacer luego la relación verbal o escrita de su viaje. He aquí la clave, el verdadero enigma de tantas correrías hechas sin motivo y sin término; he aquí la meta de este círculo; el premio de este torneo; la ignorada deidad a quien el hombre móvil dirige su misteriosa adoración (Mesonero, 1881: 3).

Se entiende: escribir el viaje es, de algún modo, prolongarlo: detener el tiempo, aquel anhelo tan acariciado y nunca conseguido por Azorín. Y estamos en el siglo XIX. Porque, aunque es en el XVIII cuando la literatura de viajes toma conciencia de sí misma como modalidad de escritura específica y diferenciada de otras, los textos de los viajeros del XVIII difieren bastante de los del XIX, en gran medida porque, si en el primero se buscaba la objetividad en lo relatado, en el XIX, y más a medida que el siglo avanza, observamos que el relato se tiñe de la personalidad, de la subjetividad del viajero individual. Lo explicaba bien Emilia Pardo Bazán cuando a finales de siglo escribía:

Mejor que Dumas; tan bien como Teófilo Gautier; antes que Amicis y Loti, supo Alarcón que el viaje escrito es el alma de un viajero, y nada más; que a los países y comarcas les infunde el escritor su propio espíritu (porque para libros de viajes objetivos, ahí están las Guías y las Descripciones geográficas, hidrográficas, arqueológicas e históricas); que el viaje escrito es género poético (entendiendo la palabra en sentido más amplio y alto), y que un libro de viajes que comunique al lector la impresión producida por una comarca en una organización privilegiada para ver y sentir... lo que no ven ni sienten los profanos es tan obra de arte como una novela (Pardo Bazán, 1892: 21).

Entiéndase que en todo lo que voy diciendo no hay claras líneas divisorias ni compartimentos estancos: en las Cartas del viaje de Asturias de Jovellanos, ya aparece el yo dando su peculiar enfoque al relato, y en muchos libros de viajeros románticos, por el contrario, pervive un deseo de objetividad o de utilidad muy dieciochesco. Pero hablando en general, y refiriéndome a la literatura española en particular, puede decirse que ahí reside la explicación de que los viajes escritos en el siglo XIX tengan más interés literario, artístico, que los del siglo precedente.

En cualquier caso, cuando Mesonero Romanos hablaba de esa comezón de viajar que percibía en su época, no se refería tanto a sus paisanos como a los viajeros franceses, ya que el párrafo citado pertenece al primer capítulo de sus Recuerdos de viaje por Francia y Bélgica en 1840 a 1841, titulado «Los viajeros franceses en España». En nuestro país, todavía muchos años después, en 1892, Emilia Pardo Bazán lamentaba la carencia de inquietud viajera en los españoles y, en consecuencia, hablaba de las narraciones de viajes como de «un ramo apenas cultivado entre nosotros»: 
En España no existe la noción estética del viaje: el que hace la maleta para salir de su casa no busca recreo, obedece a circunstancias que le imponen la necesidad de trasladarse, o la moda que obliga a un veraneo insípido, formulista, regulado de antemano por la rutina consuetudinaria. (...) El poeta que cifró la dicha en no haber visto «más río que el de su patria» español tenía que ser. Aquí no se ha modificado aún el concepto penal, digámoslo así, del viaje. Viajar es, para la inmensa mayoría, sinónimo de derroche triste, mezcla de padecimientos, privaciones, riesgos y vejámenes (Pardo Bazán, 1892: 21).

En España el género -si género es- no ha dado grandes obras, siendo, sin embargo, nuestro país el escenario de las correrías de la mayor parte de los turistas -vamos ya a llamarles así- decimonónicos, en particular franceses e ingleses. Lo que sí es un hecho es que, bastantes de los pocos españoles que viajaron entonces dejaron constancia escrita de su periplo. El resultado es una literatura de muy desigual calidad, al no ser necesario para relatar el viaje poseer buena pluma o talento literario, sino únicamente haber viajado y tener el deseo de conservar la experiencia en esa memoria de papel que es el libro.

Los españoles del XIX también fueron, como los extranjeros que nos visitaron, más viajeros que sus antepasados, y también dejaron testimonios de su deambular. El número de publicaciones, de unos y de otros, siempre en aumento, llamó la atención de algunos estudiosos a finales del siglo XIX, que comenzaron a ocuparse de recopilar e inventariar los libros de viajes por España. El nacionalismo entonces en auge fue determinante para que el elemento que diera unidad a las recopilaciones fuera el territorial. El eje vertebrador de las bibliografías no lo constituían los autores sino el territorio visitado, que era nuestro país. El primer español que intentó una recopilación fue un alicantino, el historiador y crítico Rafael Altamira, profesor de la Institución Libre de Enseñanza, que en 1896 publicó en La Ilustración Española y Americana un artículo sobre los «Libros de viajes norteamericanos referentes a España» (Altamira, 1896). Fue un primer paso no muy posterior a la ambiciosa obra de Raymond Foulché-Delbosc, Bibliographie des voyages en Espagne et en Portugal (1893) en donde recogía 858 libros de viajes desde el siglo II hasta 1895, de los cuales 640 habían sido escritos en el siglo XIX. ${ }^{2}$ La proporción, como se ve, de los textos del XIX es asombrosa. Consecuente con su título, el criterio amplio del hispanista francés para incluir una obra en su bibliografía fue el testimonio escrito del viaje realizado y no el arte literario con que estuviera relatado, de modo que la desigual calidad de los textos a la que me he referido resulta evidente. Pero gracias a él tenemos una primera gran recopilación,

2. Rafael Altamira publicaría una reseña de esta obra en La Ilustración Española y Americana el 15-X-1896. 
que fue la base que permitió a Arturo Farinelli llevar a cabo una extensa obra en cuatro volúmenes -el tercero es el dedicado al siglo XIX- titulada en su versión castellana definitiva Viajes por España y Portugal desde la Edad Media hasta el siglo XIX: nuevas y antiguas divagaciones bibliográficas (1942-1979). En esta obra Farinelli adoptó un criterio todavía más amplio que el de Foulché-Delbosc, ya que incluyó obras que, no tratando directamente de un viaje, lo contienen, como ocurre a veces con los libros de memorias.

Ya en el siglo XX se ocupó de la bibliografía de los libros de viajes por España, con un criterio exhaustivo, $\mathrm{M}^{\mathrm{a}}$ del Mar Serrano en Las guías urbanas y los libros de viajes en la España del siglo XIX: repertorio bibliográfico y análisis de su estructura y contenido. ${ }^{3} \mathrm{Y}$, desde luego, para cualquier interesado en el tema son de consulta imprescindible las bio-bibliografías publicadas en la década de los noventa por Carlos García Romeral.

Paralelamente se han ido preparando antologías de textos de viajeros ingleses, franceses, hispanoamericanos, portugueses, extranjeros en general, por España o dedicadas a una determinada región o área geográfica. Relatos de viajeros por Galicia, por La Mancha, por Andalucía, por las Islas Baleares, por las Canarias... Todavía no tenemos la dedicada a la provincia de Alicante. Y no porque no la hayan visitado muchos y notables viajeros en el siglo XIX, españoles como Pedro Antonio de Alarcón, o extranjeros como Teófilo Gautier, el viajero francés más denostado de todos, porque a él se le culpa de la imagen deformada de nuestro país que, gracias a su Voyage en Espagne ${ }^{4}$, tan lleno de color local y de tipismo, tuvieron muchos. Por cierto que Gautier llega a Alicante con una idea preconcebida, debida a un verso de Víctor Hugo en las Orientales que dice que en esta ciudad se dan cita campanarios y minaretes («Alicante aux clochers mèle les minarets»). Al no encontrarlos escribe Gautier: «El único campanario que tiene no es más que una torre muy baja y poco aparente. Lo que caracteriza a Alicante es una enorme roca que se eleva en medio de la ciudad; y esa roca, magnífica de forma, magnífica de color, está coronada por una fortaleza y flanqueada con una garita colgada sobre el abismo de la manera más audaz». En su viaje a España, Alicante -que es solo un alto en la travesía por mar de Cartagena a Valencia- ocupa un único,

3. Publicado como Viajes de papel: (repertorio bibliográfico de guías y libros de viajes por España, 1800-1902), Barcelona, Publicacions de la Universitat de Barcelona, 1993.

4. Gautier viajó a España en 1840 y publicó su relato en volumen -previamente lo había hecho en la prensa- con el título, que fue muy criticado, de Tra los montes (París, V. Magen, 1843). En la segunda edición cambió el título por Voyage en Espagne (París, Charpentier, 1845).

Anales, 24, 2012, pp. 67-82 
pero extenso párrafo. ${ }^{5}$ Años más tarde, en 1862, también visitarán Alicante Charles Davillier y Gustavo Doré. ${ }^{6}$ Siguen una ruta inversa a la de Gautier (desde Francia, por Perpiñán a Barcelona, de ahí a Valencia y de Valencia a Alicante, después de visitar Alcoy y Albacete). Los lugares comunes estaban tan extendidos que curiosamente citan el mismo verso de Víctor Hugo en sus Orientales al referirse a la ciudad, y también les desilusiona no encontrar «otra cosa que una ciudad comercial, lo que no le impide tener, como casi todas las ciudades de España, la pretensión de remontarse hasta tiempos fabulosos». De los comentarios que hacen se desprende que se han documentado previamente y por eso se encuentran bastante desencantados: «Un hecho cierto es que el Alicante que nosotros vimos es una ciudad completamente moderna. A pesar de haber dado un concienzudo paseo, no pudimos descubrir el menor trozo de antiguas construcciones, ningún monumento árabe y ni siquiera un edificio de la Edad Media o del Renacimiento». Describen el ayuntamiento, la catedral -donde sólo se fijan en el tema de un cuadro: el martirio de santa Águeda-, y caminan hasta el extremo de uno de los dos muelles para tener una buena vista de la ciudad. Observan que «el clima de Alicante pasa por ser uno de los más secos y más templados de Europa. No se conocen allí los inviernos y se asegura que el termómetro jamás ha estado debajo de cero.» Y terminan sus líneas dedicadas a la ciudad comentando que «En suma, los méritos más sólidos de Alicante nos parecieron primero sus famosos vinos y luego sus turrones de almendras, que pueden rivalizar con las peladillas de Alcoy. Estos productos gastronómicos bien merecen ser citados en un país que no ha pasado nunca por ser la tierra de las golosinas.»

\section{$* * *$}

El elemento que da unidad a toda la literatura de viajes es el viaje mismo, pero es necesario algo más para hablar de literatura. En el relato de viaje que pretende, y tal vez logra, la objetividad científica con dificultad encontramos arte literario. Por el contrario la subjetividad del viajero-narrador, que se va acentuando a medida que el siglo avanza, aporta literariedad al relato, de forma que podría decirse que los relatos de viajes -concretamente los escritos por españoles- tienen más interés literario en el siglo XIX que en el XVIII. Porque de esa mayor subjetividad deriva la utilización de determinados recursos narrativos, tanto en la dispositio como en la elocutio. Los mismos autores

5. Lo relativo a Alicante en Gautier, 1845: 400-401.

6. Su Voyage en Espagne también se publicó primero en la prensa y posteriormente en volumen. 
son conscientes de ello, aunque desconozcan las reglas del juego, los patrones del género, y no sepan bien cómo calificar sus propias obras. Modesto Lafuente, por ejemplo, titula la suya Viajes de fray Gerundio por Francia, Bélgica, Holanda y orillas del Rhin (1859). Al comienzo del primer tomo se dirige al lector, enviándole «esta serie de artículos de viaje, que no sé cómo llamar, si relación, o reseña, o apuntes, o memorias, u observaciones, o recuerdos: ni sé en verdad qué nombre merezcan, pero tú les darás el que en tu discreción y buen juicio te parezca más acomodado, o bien los dejarás sin nombre, que por eso ni ellos ni yo nos habremos de querellar».

La literatura de viajes a la que me vengo refiriendo es la que tiene como base un viaje real -dejamos ahora a un lado los viajes de ficción- y suele estar escrita en prosa. Los relatos de viajes en verso son excepción, aunque los hay, y de autores bien conocidos, como Zorrilla, que en el que titula iA escape $y$ al vuelo! (1888), relata su recorrido en tren por el norte de España: Guetaria, Zumaya, Iziar, Deva, Motrico, Zarauz, Azpeitia, Loyola... En prosa o en verso, suele ser una característica común la utilización de la primera persona narrativa, del singular o del plural, con identificación de autor y narrador, que es al mismo tiempo el viajero que relata su propia experiencia. En el siglo XIX apenas se encuentran excepciones a esta constante, como son los viajes relatados en tercera persona. La de viajes es, de algún modo, literatura de la experiencia.

Desde el punto de vista formal, la estructura del relato de viajes suele ser cerrada y el hilo de la narración lineal, en orden sucesivo, de principio a fin, aunque se intercalen incisos, excursos o digresiones, que muchas veces se agradecen y otras en cambio entorpecen el hilo de la lectura. En cuanto a la forma de contar el viaje viene dada por la finalidad del mismo. No tiene el mismo tono -y no digamos contenido- el viaje dieciochesco, sea científico, histórico o artístico, siempre en busca de la utilidad, que el periodístico de la segunda mitad del XIX. Pedro Antonio de Alarcón, al comienzo del Diario de un testigo de la Guerra de África (1859) manifestaba que su propósito al escribirlo era «hacer viajar conmigo al que me lea; identificarle con mi alma; obligarle a experimentar mis sobresaltos y alegrías, mis trabajos y satisfacciones; comunicarle aquello que más pueda importarle». Ya no se trata de informar al lector, sino de involucrarle en el viaje mismo por el modo de relatarlo y por los recursos literarios derivados de ese propósito. El viajero, que hoy conserva la memoria de su deambular en fotografías o grabaciones, la guardaba entonces en las páginas de un diario, de unas memorias, de unos recuerdos. A fin de cuentas, un viaje es un retazo de la vida del viajero y es palpable la relación de la literatura de viajes con la autobiográfica o literatura 
del yo. Pedro Antonio de Alarcón, precisamente en un artículo sobre Alicante (1858), escribió que «un viaje es una vida en abreviatura». Efectivamente, el viaje es una de las metáforas de la vida humana, como también lo son el camino, el sueño o el teatro. Y esta vinculación de la literatura viajera con la autobiográfica es patente en los títulos de muchas obras. Enrique Gil y Carrasco redactó en 1844 un Diario de viaje, en donde relató su recorrido de Madrid a Berlín, pasando por París, Lille, Bruselas, Gante, Brujas, Ostende... Emilio Castelar, sin embargo, escribió sus Recuerdos de Italia (1872-1876) después de haber regresado, con un sosiego que le permitía evocar y reflexionar sobre los lugares que había visitado. Por eso explica que mezclará «a las consideraciones filosóficas, históricas, literarias y artísticas, consideraciones políticas: que al cabo la política no es otra cosa sino la cristalización de todas las ideas, y su resultado social.» En otras ocasiones el viajero relata su experiencia en forma de cartas, estableciendo así otro nexo, ahora con la literatura epistolar. Las Cartas desde Rusia de Juan Valera, que comienzan el 26 de noviembre de 1856, están consideradas por algunos, junto con el Diario de un testigo de la Guerra de África de Alarcón, y con las Cartas finlandesas de Ganivet (1898), una de las mejores piezas de nuestra literatura de viajes.

Se discute todavía si ésta es un género o un subgénero literario. Villar Dégano (1996) lo ha calificado de «paraliteratura», porque no encaja en los moldes de la literatura canónica. Pero también puede considerarse de algún modo parte de la narrativa que no es de ficción, o una de las que en una ocasión llamé «formas literarias de la materia histórica» (Freire, 1991: 257), como pueden serlo las antiguas crónicas, o las más modernas biografías, autobiografías, diarios, recuerdos, memorias, epistolarios, así como las dieciochescas oraciones fúnebres y otros textos semejantes escritos con voluntad literaria, porque, como decía Emilia Pardo Bazán, «las guías y los itinerarios son otra cosa».

Ya a principios del XIX Alexandre Laborde, un francés de ascendencia española, autor de una magna obra, el Voyage pittoresque et historique de l'Espagne (1806-1820) en cuatro volúmenes, con bellas ilustraciones, publicó además un Itinéraire descriptif de l'Espagne (1808) que pudiera servir de guía a quienes visitaran nuestro país. Laborde, que publicó el primer tomo del Voyage pittoresque en 1806, no contaba con que dos años después estallaría la Guerra de la Independencia entre nuestro país y el suyo. No obstante, sacó los tomos dos y tres en 1811 y 1812: para el último hubo de esperar a 1820, el primer año del trienio liberal. Pero con su obra, especialmente con su Itinéraire, prestó una ayuda impagable al ejército francés a la hora de conocer el territorio que pretendía invadir. 
Aquellos franceses que vinieron a España con motivo de la Guerra de la Independencia se llevaron su propia visión de nuestro país, visión parcial y sesgada, que plasmaron en sus libros de memorias. No conozco directamente muchas de esas obras, entre las que suelen destacarse -sigo en esto a Arturo del Hoyo (1991) - «los Souvenirs del artillero Bapts, las Mémoires del capitán de fragata Pierre Base, las del sargento Bourogne, las escenas de la vida militar trazadas por el oficial polaco Brant, el diario del mariscal Castellone... y, sobre todo, las famosas Mémoires d'un apothicaire (1808-1814), que fueron escritas por el boticario Marie-Sebastien Blaze» ${ }^{7}$, que vivió parte de la guerra en Madrid y posteriormente fue hecho prisionero, pasando numerosas vicisitudes. Morel-Fatio achacaba a Blaze y a sus compañeros la difusión de muchos tópicos sobre nuestro país, que ya eran lugar común en la época romántica, cuando el Barón Taylor vino a España (1835), enviado y pagado por Luis Felipe de Orleans, con la misión de adquirir para su país cuantos objetos artísticos pudiese, aprovechando la crisis económica española y la desamortización. Era la tercera vez que Taylor nos visitaba. Y lo hacía sobre seguro, porque conocía bien el país, sobre el que ya había publicado su Voyage pittoresque en Espagne, en Portugal et sur la côte d'Afrique, de Tanger à Tétouan (1826-1832). La obra de Taylor está inspirada en la de Laborde, pero la de Taylor hace más hincapié en lo pintoresco que en lo artístico. Cuando Taylor viene a mediados de la década de los treinta, entra en contacto con Eugenio de Ochoa, Federico de Madrazo y otros jóvenes románticos, y en 1836 aparece una reseña de su viaje en El Artista, la publicación más emblemática del Romanticismo español. Por esa misma época visitaron España gran cantidad de «curiosos impertinentes», como Ian Robertson ha denominado en el título de una obra suya (Robertson, 1988) a aquellos viajeros británicos (George Borrow, Richard Ford, etc.) que nos observaban y que en los libros que escribían a su regreso contribuían a difundir su peculiar imagen de nuestra tierra, aquella que nuestros escritores costumbristas intentaron corregir con las mismas armas, o sea, con la pluma, con la literatura. Arturo del Hoyo, en el prólogo citado, considera que Edgar Quinet, un francés que vino a España en 1843, cuando la mayoría de edad de Isabel II -también por esas fechas nos visitó Alejandro Dumas- es el más moderno de los viajeros franceses del siglo XIX, precisamente porque no dio de España solamente la visión pintoresca, sino que en su libro Mes vacances en Espagne (1846) supo contextualizar ese pintoresquismo en el momento cultural, social y político en que escribía.

7. De éstas existe una edición en castellano de 2008.

Anales, 24, 2012, pp. 67-82 
En cualquier caso, la deformación de nuestra imagen venía de antiguo, pues ya Antonio Ponz en el siglo XVIII, en el prólogo a su Viaje fuera de Espa$\tilde{n} a$ (1785) denunciaba las muchas falsedades que propalaban algunos extranjeros que nos visitaban, cuando recogían por escrito su experiencia viajera. Y Cadalso en sus Cartas marruecas, publicadas en el Correo de Madrid en 1789, lamentaba «la ligereza de los que por cortas observaciones propias, o tal vez sin haber hecho alguna, y sólo por la relación de viajeros poco especulativos, han hablado de España».

La imagen que crearon de España aquellos extranjeros pervivía cuando Edmundo de Amicis nos visitó en 1871. Al comienzo de su libro España ${ }^{8}$ cuenta cómo sus amigos, al despedirse de él en Italia, le piden que les traiga como recuerdo una espada de Toledo, una botella de Jerez, una guitarra, un sombrero andaluz, un puñal. Pero la imagen poco fiel no sólo consistía en ese tipo de referencias a lo tópico y a lo típico. Y si no leamos la descripción que la condesa Valérie de Gasparin hace de Alicante en su libro A travers les Espagnes: Catalogne, Valence, Alicante, Murcie et Castille (1869²), editado en castellano en 1875:

Estamos en África: asomaos a la ventana y mirad. Sol grande y esplendoroso; mar grande también y tranquilo. A la derecha, playas arenosas que van descendiendo hacia el sur, hasta que desaparecen en un horizonte luminoso; a la izquierda, rocas cortadas, ásperas y desnudas sostienen una ciudadela morisca: todo resplandece y fulgura, todo es blanco.

En la época romántica, el interés por las ruinas y por el pasado da lugar a aquellos viajes artístico-literarios, en los que al texto acompañaban los dibujos y grabados, ya que el escritor viajaba siempre con un dibujante. Al evocarlos parece inevitable mencionar a Bécquer, pero no me detendré en ellos porque son, tal vez, los mejor estudiados del siglo XIX ${ }^{9}$. Con una idea semejante, pero aprovechando los adelantos técnicos, en los que el siglo XIX no fue escaso, Pedro Antonio de Alarcón, cuando preparaba su viaje a África para ser testigo de aquella guerra y escribir su Diario, buscó como acompañante a un fotógrafo «a fin de sacar panoramas de los terrenos que recorriéramos, retratos de cristianos, moros y judíos, y vistas de las ciudades que conquistásemos». Sin embargo, no le sirvió de mucho "pues las continuas lluvias y otros contratiempos me demostraron que era casi imposible sacar vistas en aquellos parajes y circunstancias.» En todo caso, el Diario de un testigo de la guerra de África tiene gran interés porque Alarcón suplió con la pluma lo que

8. La primera edición española (Amicis, 1877) fue la que tradujo Augusto Suárez de Figueroa a partir de la cuarta edición italiana publicada en Florencia.

9. Una buena caracterización de éstos en: Rubio Jiménez, 1992. 
no captó la cámara, y su comparación con la Crónica de la Guerra de África de Emilio Castelar (1859), autor por otra parte de interesantes obras de literatura de viajes, permite apreciar bien la diferencia entre las diversas modalidades del género de acuerdo con la finalidad que persigue cada autor.

La mejora de las comunicaciones y la llegada del ferrocarril a mediados de siglo invitaban a trasladarse de un lugar a otro con mayor comodidad que en las antiguas diligencias o a lomos de caballería. Es sabido que la primera línea de ferrocarril que existió en España fue la de Barcelona a Mataró, inaugurada en 1848, seguida de la de Madrid a Aranjuez, en 1851. Los adelantos en este ramo no habían hecho más que empezar, y a partir de ese momento las alusiones al ferrocarril serán frecuentes en la literatura de viajes. Recuerdo cómo Emilia Pardo Bazán comenta, cuando viaja, enviada por El Imparcial, a la Exposición Universal de París en 1900 -antes había asistido como corresponsal de La España Moderna a la de 1889- que «ahora el tren continúa más allá de la estación de Orleans, y deja en el centro de París a los viajeros.»

La inauguración de una nueva línea de ferrocarril, el ferrocarril del Mediterráneo, es el motivo por el que Pedro Antonio de Alarcón viaja a Alicante, a donde llega el 25 de mayo de 1858, como periodista, después de un delicioso trayecto desde Madrid. Las crónicas que con este motivo publicó en el Museo Universal están condicionadas por la línea del periódico, fenómeno con el que nos encontramos con frecuencia al estudiar la literatura de viajes en prensa en la segunda mitad del siglo. Al no tratarse de un periódico político, las crónicas de Alarcón habrán de ser puramente literarias, a pesar del carácter de aquel acto, al que asiste la reina Isabel II y la familia real, varios ministros y otras personalidades de la vida pública del país. Alarcón centra su artículo en los festejos (muchachas alicantinas que agasajan a los reyes, altares que se han preparado, locomotoras ataviadas como toros sagrados...), dejando de lado el cariz político del acontecimiento y, desde luego, la descripción de Alicante, que también omite. Sin embargo, cae en una tentación frecuente en los escritores de viajes: aquella que consiste -hablando metafóricamente, con una metáfora muy decimonónica- en utilizar más el pincel que la pluma: esto es, describir más que relatar, ya que pasa como sobre ascuas por escenas tan vivas y coloristas como los fuegos artificiales, la regata entre dos botes pertenecientes uno a un buque de guerra español y otro a una fragata francesa, la celebración del cumpleaños de la reina Victoria o la visita a la finca del marqués de Molins.

Este es un ejemplo de cómo el medio condiciona la escritura. Pero también la favorece. Lo vemos con claridad en el caso de Emilia Pardo Bazán, que encuentra el cauce para su literatura de viajes en la crónica de prensa, 
llegando a dar las claves de su modo de entender y practicar este género periodístico. Ella, que nunca hubiera publicado un libro de viajes al estilo tradicional, porque no le gustan «las híbridas obrillas viatorias, las 'Impresiones' y 'Diarios', donde el autor nos refiere sus éxtasis ante una catedral o punto de vista, y a renglón seguido cuenta si acá dio una peseta de propina al mozo, y si acullá cenó ensalada, con otros datos no menos dignos de pasar a la historia y grabarse en mármoles y bronces» (Pardo Bazán, 190?: 5), publica nada menos que siete libros de viajes ${ }^{10}$, que primero vieron la luz en la prensa en forma de artículos. La amenidad de estas obras radica en el modo de entender cómo ha de ser una crónica redactada para el periódico:

La necesidad de escribir de todo, y deleitando e interesando, aunque se traten materias de suyo indigestas y áridas, obliga a nadar a flor de agua, a presentar de cada cosa únicamente lo culminante, y más aún lo divertido, lo que puede herir la imaginación o recrear el sentido con rápida vislumbre, a modo de centella o chispazo eléctrico. En crónicas así, el estilo ha de ser plácido, ameno, caluroso e impetuoso, el juicio somero y accesible a todas las inteligencias, los pormenores entretenidos, la pincelada jugosa y colorista, y la opinión acentuadamente personal, aunque peque de lírica, pues el tránsito de la impresión a la pluma es sobrado inmediato para que haya tiempo de serenarse y objetivar. En suma, tienen estas crónicas que parecerse más a conversación chispeante, a grato discreteo, a discurso inflamado, que a demostración didáctica. Están más cerca de la palabra hablada que de la escrita (Pardo Bazán, 1899: 11-12).

A medida que el siglo camina hacia su fin son más numerosos los libros españoles de viajes que nacen como recopilación de artículos o crónicas publicadas previamente en la prensa periódica. Así también había nacido en Francia el Viaje por España de Teófilo Gautier, primero en La Presse y después en la Revúe de Deux Mondes, y el viaje de Davillier y Doré había ido saliendo en la revista de viajes de la editorial Hachette, Le Tour du Monde. La práctica ya era común cuando Emilio Castelar publica Un año en París (1875), donde reúne crónicas que «vieron la luz en los folletines de varios periódicos americanos, ya olvidados y perdidos» desde septiembre de 1866 hasta finales de 1867. Viajes de un cronista, de José Ortega Munilla (1892) es la recopilación en un mismo tomo de crónicas relativas a varios viajes («Tánger», «Un mes en Berlín», «Por las costas andaluzas», «Siluetas gaditanas», «Roma»...) realizados años atrás y escritas, según él, «a escape, sin átomos de pretensión artística, más con propósitos de reporter que con los de literato.»

10. Un estudio de éstos en Freire,1999.

Anales, 24, 2012, pp. 67-82 
Los relatos de viajes que los españoles realizaron por España son menos ambiciosos en general, aunque no menos interesantes, que los referidos al extranjero. Algunos, como Cuarenta leguas por Cantabria de Galdós (1879), o Desde la montaña de Emilia Pardo Bazán (1894), se han reeditado en época reciente. A la misma zona geográfica está dedicado Costas y montañas de Amós de Escalante (1871), que lo firmó con su seudónimo, Juan García. Un título parecido tiene la obra de José Ortega Munilla, Mares y montañas (1887), donde habla de Vigo, San Sebastián, Panticosa, Linares, Los Pirineos y Bilbao. También de Amós de Escalante, que firma en esta ocasión con su verdadero nombre, es Del Manzanares al Darro (1863), donde relata un viaje desde Madrid, deteniéndose en diversas poblaciones manchegas y andaluzas. Y también suyo, y con el mismo esquema en el título -de río a río- es Del Ebro al Tíber (1864), con más carga autobiográfica, en donde relata un viaje a Italia en el que coincide, en Roma, con Pedro Antonio de Alarcón, que a su vez cuenta su propia andadura en De Madrid a Nápoles (1861).

Los libros de españoles por el extranjero resultan (o resultaban en su tiempo) más atractivos, por lo desconocido de los lugares visitados, o de sus costumbres e incluso por las reflexiones y reacciones que esos lugares suscitan en un viajero de nuestro propio país. Resulta bastante común que la actitud del viajero, extranjero o español, sea muy diferente en su propia patria y fuera de ella, donde suele ser más espectador que protagonista.

Por esos mundos recorren itinerarios semejantes diversos españoles a lo largo del siglo XIX. Si Mesonero Romanos había escrito sus Recuerdos de viaje por Francia y Bélgica en 1840 a 1841, poco tiempo después de haber viajado, en 1844 también atravesaría Francia y los Países Bajos, camino de Berlín, Enrique Gil y Carrasco, y que redactaría su Diario de viaje. A mediados de siglo Modesto Lafuente publicaba en dos tomos los también mencionados Viajes de Fray Gerundio por Francia, Bélgica, Holanda y orillas del Rhin, sin tener noticia, por lo visto, de las dos obras anteriores, ya que advierte al comienzo de la suya que escribe «sin pretensiones de ningún género. Yo no me he propuesto más que dar a conocer a mis compatriotas llana y sencillamente algunas cosas y costumbres de los pueblos y países que he recorrido, y en que no había visto ocuparse otras plumas, que a haber querido tomarse este trabajo, lo hubieran desempeñado mucho mejor que yo.»

También fueron meta de muchos viajeros los Santos Lugares, y algunos escribieron al regreso la crónica de su peregrinación. Otros viajaron comisionados o por motivos profesionales, como Valera, que se trasladó a Washington y a Rusia con un cargo diplomático. Pero un motivo para viajar se añade 
en el XIX que no existía en el siglo anterior, y es la visita a las Exposiciones Universales, que ya en sí mismas son un auténtico viaje por el mundo conocido sin moverse de un mismo lugar, que puede ser París, Viena o Barcelona. De los libros escritos a raíz de estas exposiciones me ocupé hace años en una primera aproximación al tema (Freire, 1997). En la actualidad (2011) una alumna prepara una prometedora tesis doctoral sobre las Exposiciones Universales del siglo XIX en la literatura de viajes española, que supondrá un avance en el conocimiento de ese vasto mundo en el que todavía existen tantos territorios vírgenes.

\section{BIBLIOGRAFÍA}

Alarcón, Pedro Antonio de, «Alicante y Valencia. Apuntes de viaje. Episodios no políticos», El Museo Universal, junio de 1858.

ALARCÓn, Pedro Antonio, Diario de un testigo de la guerra de África, Madrid, Gaspar y Roig, 1859.

AltAmiRA, Rafael, «Libros de viajes norteamericanos referentes a España» en La Ilustración Española y Americana, 22-V-1896.

Amicis, Edmondo de, España. Viaje durante el reinado de Don Amadeo I, Madrid, Imp. y Est. de El Imparcial, 1877.

BLAZE, Sebástien, Un boticario francés en la guerra de España (1808-1814), Madrid, Trifaldi, 2008.

Castelar, Emilio, Crónica de la Guerra de África, Madrid, Imprenta de V. Matute y B. Compagni, 1859.

Castelar, Emilio, Recuerdos de Italia, Madrid, Oficinas de La Ilustración Española y Americana, 1872-1876, 2 vols.

Castelar, Emilio, Un año en París, Madrid, Establecimiento Tipográfico de El Globo, 1875.

FARINELLI, Arturo, Viajes por España y Portugal desde la Edad Media hasta el siglo XIX: nuevas y antiguas divagaciones bibliográficas, Roma, Reale Accademia d'Italia, 1942-1979, 4 vols.

FoulChÉ-DelbosC, Raymond, Bibliographie des voyages en Espagne et en Portugal, París, H. Welter, 1893.

Freire LóPEZ, Ana María, «La función de la anécdota en la caracterización del personaje histórico», en Jacqueline Covo, (ed.), La Construction du personnage historique (Aires hispanique et hispano-américaine), Lille, Presses Universitaires de Lille, 1991, pp. 257-264.

FreIRE LóPEZ, Ana María, «Les Expositions Universelles du XIXe siècle dans la Littérature espagnole: La vision d'Emilia Pardo Bazán», en Vision de l'Autre dans une Europe des cultures aux XVIIIe, XIXe et XXe siècles, Les Cahiers du CICC, nº 3, Mai 1997, págs. 124-133. 
Freire López, Ana María, «Los libros de viajes de Emilia Pardo Bazán: el hallazgo del género en la crónica periodística», en SALVADOR GARCía CaSTEÑEDA, (ed.), Literatura de viajes. El Viejo Mundo y el Nuevo, Madrid, Castalia-Ohio State University, 1999, págs. 203-212.

Ganivet, Ángel, Cartas finlandesas, Granada, Viuda e Hijos de Sabatel, 1898.

García-Romeral PÉReZ, Carlos, Bio-biliografía de viajeros españoles (siglo XIX), Madrid, Ollero \& Ramos Editores, 1995

García-Romeral Pérez, Carlos, Bio-biliografía de viajeros españoles (siglo XVIII), Madrid, Ollero \& Ramos Editores, 1997

GARCíA-ROMERAL PÉREZ, Carlos, Bio-bibliografía de viajeros por España y Portugal (siglo XIX), Madrid, Ollero \& Ramos, 1999.

Gasparin, Valérie, A travers les Espagnes: Catalogne, Valence, Alicante, Murcie et Castille, París, Michel Lévy frères, $1869^{2}$.

Gautier, Théophile, Voyage en Espagne, París, Charpentier, 1845.

Gautier, Théophile, Tra los montes, París, V. Magen, 1843.

Gil y CARrasco, Enrique, Diario de viaje en Obras en prosa de D. Enrique Gil y Carrasco coleccionadas por Joaquín del Pino y Fernando de la Vera e Isla; precedidas de un prólogo y de la biografía del autor, Madrid, Imp. de la Viuda e Hijo de E. Aguado, 1883, tomo II.

GÓMEZ DE LA SERnA, Gaspar, Los viajeros de la Ilustración, Madrid, Alianza Editorial, 1974.

Hoyo, Arturo del, Prólogo a la obra del barón Charles DAVILlier, Viaje por España, ilustrada por Gustavo Doré, Madrid, Ediciones Giner, 1991, 2 tomos.

LABORDE, Alexandre, Voyage pittoresque et historique de l'Espagne, París, impr. de P. Didot l'aîné, 1806-1820, 4 vols.

LABORDE, Alexandre, Itinéraire descriptif de l'Espagne, París, H. Nicolle, Lenormant, 1808.

LAFUENTE, Modesto, Viajes de fray Gerundio por Francia, Bélgica, Holanda y orillas del Rhin, México, Imprenta de Andrade y Escalante, 1859.

Mesonero Romanos, Ramón de, Recuerdos de viaje por Francia y Bélgica (Nueva edición corregida y aumentada), Madrid, Oficinas de La Ilustración Española y Americana, 1881.

OrTEGa Munilla, José, Viajes de un cronista, Madrid, Manuel Fernández y Lasanta Editor, 1892.

PARdo BAZÁN, Emilia, «Pedro Antonio de Alarcón», en Nuevo Teatro Crítico, núm. 13, enero de 1892.

PARdo BAZÁn, Emilia, Por la España pintoresca, Barcelona, López Editor, Librería Española, [1895].

PARdo BAZÁn, Emilia, Al pie de la Torre Eiffel, Madrid, Establecimiento Tipográfico de Idamor Moreno, [1899] (Tomo XIX de Obras Completas). 
PARDo BAZÁn, Emilia, Un viaje de novios, Madrid, R. Velasco, imp. [190?] (Tomo XXX de Obras Completas).

PONZ, Antonio, Viaje fuera de España, Madrid, Ibarra, 1785.

QUINET, Edgar, Mes vacances en Espagne, París, Comptoir des imprimeurs unis, 1846.

ROBERTSON, Ian, Los curiosos impertinentes: viajeros ingleses por España desde la accesión de Carlos III hasta 1855, Barcelona, Serbal, 1988.

RUBIO JIMÉNEZ, Jesús, «El viaje artístico-literario: Una modalidad literaria romántica», Romance Quarterly, 39 (febrero de 1992), pp. 23-31.

SERrANO, Ma del Mar, Viajes de papel (repertorio bibliográfico de guías y libros de viajes por España, 1800-1902), Barcelona, Publicacions de la Universitat de Barcelona, 1993.

TAYLOR, barón Justin, Voyage pittoresque en Espagne, en Portugal et sur la côte d'Afrique, de Tanger à Tétouan, París, Gide fils, 1826-1832, 3 vols.

VILlar DÉGANo, Juan Felipe, «Paraliteratura y libros de viajes», en Compás de Letras 7 (1996), pp. 15-32.

Zorrilla, José, ¡A escape y al vuelo!, Madrid, R. Velasco impresor, 1888.

Fecha de recepción: 19-01-2012

Fecha de aceptación: 30-03-2012 